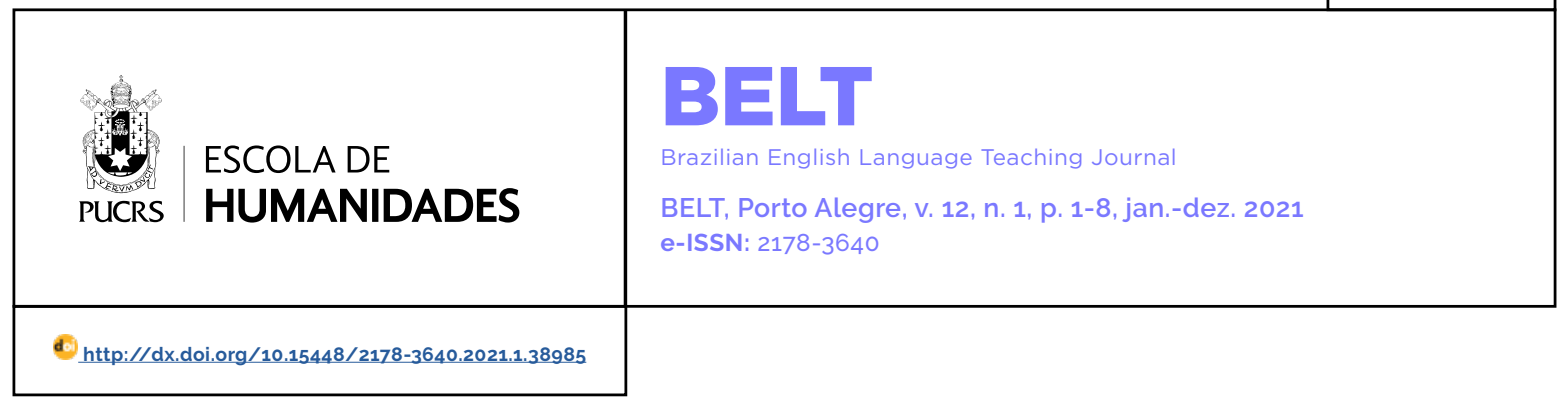

SEÇÃO: ARTIGO

\title{
O lugar da tradução no ensino-aprendizagem de inglês do século XXI
}

\author{
The place of translation in the 21st century English teaching-learning
}

Lucas Alves Selhorst ${ }^{1}$

orcid.org/0000-0001-6667-3281

lucasselh@hotmail.com

Recebido em: 28 ago. 2020

Aprovado em: 17 ago. 2021. Publicado em: 27 out. 2021.

\section{(c) (i)}

Artigo está licenciado sob forma de uma licença Creative Commons Atribuição 4.0 Internacional.
Resumo: Em que pese as críticas que podem ser feitas ao uso da tradução no ensino-aprendizagem de inglês, ela ainda é muito usada, de diferentes formas. Considerando as controvérsias desse tema, essa é uma pesquisa bibliográfica que tem o objetivo de entender o lugar da tradução no processo de ensino-aprendizagem de língua inglesa do século XXI. Para além dos livros e trabalhos científicos, também buscou-se olhar para a Base Nacional Comum Curricular (BNCC), já que esse é o documento normativo mais recente para a elaboração de curriculos e de propostas pedagógicas no Brasil. A tradução como método apresenta fragilidades, considerando que a capacidade dos métodos de serem suficientes frente aos diversos desafios que se impõem vem sendo questionada, esse, o mais antigo, pode ser visto como uma herança que já não faz mais sentido. Já como recurso, se verificou que a tradução se situa melhor. Podendo colaborar para o aprendizado da lingua inglesa, para o desenvolvimento de percepções linguísticas, e da consciência que envolve diversos aspectos tanto da língua inglesa, quanto da língua materna, desde que seja pensada como um recurso significativo, atual, contextualizado e que leve em conta as particularidades e necessidades dos alunos.

Palavras-chave: ensino-aprendizagem de inglês, tradução, pós-método

Abstract: Despite the criticisms that can be made of the use of translation in teaching and learning English, it is still widely used, in different ways. Recognizing the controversies of this theme, this bibliographic research aims to understand the place of translation in the 21st century English teaching-learning process. In addition to books and scientific papers, we also sought to look at the National Common Curricular Base (BNCC), since this is the most recent normative document for the development of curricula and pedagogical proposals in Brazil. Translation as a method presents weaknesses, considering that the ability of the methods to be adequate in the face of the challenges that are being posed has been questioned, this, the oldest, can be seen as a legacy that no longer makes sense. As a resource, it was found that the translation is in a better situation. Being able to collaborate for the English language learning, for the development of linguistic perceptions, and of the awareness that involves several aspects of the English language, as well as the mother tongue, as long as it is thought of as a significant, current, contextualized resource that takes into account the particularities and needs of students. Keywords: english teaching and learning, translation, post-method

Várias reflexões e discussões podem ser feitas acerca da tradução. Benjamin (2018) demonstra preocupação em relação à capacidade da tradução de corresponder à essência da obra original e diz que a tradução é uma forma pela qual as pessoas se confrontam com a estranheza das linguas. Duas dicotomias são fundamentais na discussão sobre tradução e corroboram a preocupação de Benjamin (2018), como explicam Bergmann e Lisboa (2013): a da traduzibilidade versus a da intraduzibilidade; e a da tradução palavra por palavra versus a da tradução pelo sentido. 
A tradução, no entanto, nem sempre é um trabalho profissional que se debruça sobre uma obra. Ela também pode ser aplicada como um recurso didático no processo de ensinoaprendizagem de uma lingua, quando assume outras características e pode ser chamada de tradução pedagógica, como afirma Terra (2010).

De forma mais ampla, a tradução pode ser dita como um método de ensino-aprendizagem de linguas. Dentre os métodos de ensino de línguas, o mais antigo, conforme Leffa (2012), é o método da tradução e da gramática. O autor explica que quando se criaram escolas, na época do Império Romano, o Latim se tornou uma língua internacional e, para ensiná-la, usou-se a tradução quase que exclusivamente, já que a base deste processo era decorar as palavras em Latim e associar com palavras da lingua materna.

O método da tradução e da gramática não foca na compreensão, mas apenas na tradução, na leitura e no estudo das regras gramaticais, segundo Marques (2012). O uso da tradução dentro desse método é considerado pela autora como negativo, pois priva os alunos do uso da linguagem coloquial, espontânea, não planejada, da riqueza da língua falada e da complexidade da compreensão oral.

Sobre essa aprendizagem que relegaria a linguagem coloquial e a oralidade, Corrêa (2017) diz que há uma ideia, que é comumente proferida e largamente percebida, e, portanto, representa em grande parte uma verdade, de que as escolas, isto é, escolas regulares, sobretudo as públicas, não possibilitam a comunicação e o uso da língua inglesa. Assim sendo, somente aqueles que podem pagar escolas de idiomas ou viagens teriam esse direito garantido.

Considerando as inúmeras discussões em torno da tradução como recurso didático e como um método de ensino de inglês, essa pesquisa busca responder a seguinte pergunta: qual é o lugar da tradução no processo de ensinoaprendizagem de língua inglesa do século XXI?

Estudar e aprofundar discussões sobre o processo de ensino-aprendizagem de inglês no Brasil, métodos e recursos utilizados, é, portanto, essencial para buscar um ensino de inglês de qualidade, que promova a democratização do saber e da língua e que faça o País avançar em relação à diminuição de diferenças e marcações sociais excludentes que atravessam e são atravessadas pela educação.

Deste modo, o objetivo geral dessa pesquisa é entender o lugar da tradução no processo de ensino-aprendizagem de língua inglesa do século XXI. Para isso, os objetivos específicos são: discutir a determinação de um método para as aulas de inglês; refletir acerca da tradução como método de ensino-aprendizagem de inglês; e analisar a tradução como recurso didático das aulas de inglês.

\section{A tradução e o ensino-aprendizagem de inglês}

Ao longo do século XIX, como relata Pontes (2014), o modelo de ensino que era utilizado até então para o ensino de Latim, o método de gramática e de tradução, estendeu-se para o ensino das línguas modernas.

Por ser considerado o mais antigo, o método da tradução e da gramática também é conhecido como método tradicional, como explica Furlanetto (2019), que o caracteriza pela utilização de forma preponderante da estrutura da língua, trabalhando as habilidades de leitura, tradução e escrita como bases fundamentais, de forma a utilizar a língua materna do aluno como ponte para que os significados da lingua-alvo sejam entendidos por meio de memorização e de estruturas gramaticais.

Para compreender o uso da tradução como método, é importante entender o que é um método de ensino. Uphoff (2008) diz que tradicionalmente se entende método como um conjunto de regras e de princípios a serem utilizados com um propósito, e chama atenção para a etimologia da palavra, que vem do grego methodos, que significa "caminho que leva a um determinado destino".

Pontes (2014) diz que novos métodos surgiram em substituição e oposição ao uso da tradução, principalmente, por conta de uma crença que a tradução causaria uma interferência negativa da língua materna no processo de ensinoaprendizagem da língua-alvo, já que o estudante teria dificuldades de pensar nesta última. 
Pode-se dizer, com base em Furlanetto (2019), que nenhum método é perfeito, mas que todos têm algo a oferecer, já que as pessoas possuem diferentes inteligências e habilidades e aprendem, também, de formas diferentes. Isto é, para a autora, cada estudante se adapta melhor a algum método, técnica ou abordagem, e a compreensão acerca disso colocaria o ensino-aprendizagem de inglês na atualidade, na era do pós-método, ou seja, o professor deveria ter consciência do que está fazendo, encontrando estratégias de acordo com as necessidades dos seus alunos, sem ficar restrito a uma única maneira de ensinar.

O não uso de um único método, o pósmétodo, defendido por Furlanetto (2009), é corroborado por Sanches (2013, p. 56): "No pósmétodo, o professor tomado de conhecimento e conhecedor da realidade de cada aluno, deve criar possibilidades de aprendizagem e não alunos passivos que recebem muitas informações, mas não sabem o que fazer com elas".

Kumaravadivelu (2001) afirma que no pósmétodo os vários atores do processo de ensinoaprendizagem precisam constantemente pensare atualizar as maneiras pelas quais buscam atender as necessidades, ou seja, as demandas locais, globais, profissionais, tecnológicas, dentre outras, que podem ser compartilhadas, mas que também podem mudar de pessoa para pessoa. Para ele. uma prática pedagógica pós-método é uma prática da particularidade, já que a pedagogia da linguagem, para ser relevante, deve ser sensivel a um determinado grupo de professores, alunos e objetivos, que estão inseridos em um contexto e em um meio sociocultural particular.

Para Gomes (2012), o método da tradução e da gramática inaugura o ensino restrito a uma única abordagem, e é responsável pelo fato de que dentre as quatro habilidades comunicativas ouvir, falar, ler e escrever - a leitura tenha recebido historicamente mais atenção, já que em principio o principal objetivo do estudo de outras línguas, era a tradução e a leitura de textos clássicos ou religiosos.

Gomes (2012) destaca, no entanto, o fato de a leitura, não apenas continuar sendo importante, mas de estar ainda mais em evidência, na medida que a mera decodificação de códigos, não é mais suficiente para abarcar todas as necessidades do leitor atual, que precisa dominar um grande número de gêneros textuais, para ser capaz de assimilar a miriade de informações que recebe.

A tradução, segundo Roca (2009), leva os alunos a acreditar que podem identificar significados pela simples aplicação de método. A autora diz que se trata do uso de critérios para o estudo de línguas mortas, no ensino de línguas vivas, e que mesmo os centros de linguas, que se preocupam mais com o desenvolvimento da oralidade do que os centros educacionais (escolas e universidades), carecem de uma experiência concreta no ensinoaprendizagem de línguas, por utilizarem diálogos simulados e tradução de contextos.

Contudo, Terra (2010) diz ser preciso ressignificar a tradução, para que ela deixe de ser vista como um recurso didático retrógrado e prejudicial, e ocupe um lugar de importância no ensino-aprendizagem de línguas, como um recurso de compreensão e de apreensão destas.

Para Pertel (2009), atividades de tradução podem ser usadas para o desenvolvimento da consciência linguística, na medida em que propiciam a percepção de semelhanças e diferenças das línguas por meio de análises contrastivas:

\begin{abstract}
O exercício de analisar contrastivamente textos em lingua materna, ou seja, em português, e os traduzidos para o inglês desperta no aluno a percepção das potencialidades de cada uma delas individualmente, tanto em seu nivel semântico quanto no pragmático. A partir da experiência com o diferente, o aprendiz perceberá que não era assim tão intimo do conhecido. Na contramão, está o fato de que, através da tradução e da análise contrastiva, se compreendem as sutilezas semânticas e pragmáticas da lingua-mãe que se desnudam, e lhes apresentam o diferente. (Pertel, 2009, pp. 139-140)
\end{abstract}

Considerando a complexidade do processo de ensino-aprendizagem de inglês, Tecchio e Bittencourt (2011) defendem que a tradução, se trabalhada de maneira critica, pode ser um recurso pedagógico fundamental para o desenvolvimento de percepções face às tramas que se estabelecem entre as linguas, e que envolvem, para além do léxico e da gramática, implicações culturais, fenômenos ideológicos e filosóficos. 


\section{Metodologia}

Esta é uma pesquisa bibliográfica, portanto, tal qual a definição de Lakatos e Marconi (2017), é feita com base em fontes disponiveis, como livros, artigos cientíicos, teses, dissertações, dentre outros. Também pode-se destacar, conforme as referidas autoras, a importância de se interpretar os dados obtidos, analisando-os diante dos objetivos do trabalho.

Knechtel (2014) diz que na pesquisa bibliográfica o pesquisador conversa e debate com outros autores por meio de seus escritos, visando construir conhecimento. Para ela, a leitura é um requisito da pesquisa bibliográfica, que fornece fundamentos analíticos para qualquer outro tipo de pesquisa, ou pode, como nesta pesquisa, esgotar-se em si mesma.

Além de livros e trabalhos cientíicos, esta pesquisa também tem como uma relevante fonte de dados e análises a Base Nacional Comum Curricular (BNCC). Para pensar a tradução em sua relação com o ensino-aprendizagem de inglês no Brasil atual é fundamental olhar para a BNCC, já que conforme sua própria descrição, ela é "(...) um documento de caráter normativo que define $o$ conjunto orgânico e progressivo de aprendizagens essenciais que todos os alunos devem desenvolver ao longo das etapas e modalidades da Educação Básica (...)" (Brasil, 2017, p. 5).

\section{Tradução: método e recurso em tempos de pós-método}

Ao chamar atenção para a necessidade de se dar conta das raizes das ações que se dão em sala de aula, Uphoff (2008) corrobora as explicações de Pontes (2014) e Roca (2009) acerca do fato de o uso da tradução como método ser uma herança do ensino de línguas mortas:

No Brasil do início do século XX, apenas uma elite tinha acesso a uma educação geral básica e estudava-se as linguas sob um enfoque humanista clássico, ou seja, com o intuito de contribuir para a formação intelectual e espiritual do aluno. Por isso, valorizava-se a análise gramatical e a leitura e tradução de bons textos literários, em detrimento do domínio prático do inglês. (Uphoff, 2008, p. 10)
Uphoff (2008) também aponta para uma tendência de que professores reproduzam, em suas práticas pedagógicas, aquelas utilizadas pelos seus professores quando eles eram alunos, sobretudo se o ambiente escolar não oferecer muitas condições para inovação, como é a realidade de grande parte do sistema público de educação no Brasil.

A tradução, como explica Lucindo (2006), é uma atividade de reexpressão do sentido e, portanto, de comunicação, no entanto, a autora diz que não se recomenda que seja usada como um método, nem mesmo como uma atividade principal das aulas de inglês.

Pode-se pensar que quando o método da tradução e da gramática surgiu, o objetivo da aprendizagem da língua estudada, era condizente com o método; no entanto, atualmente um método não consegue dar conta das exigências comunicativas que a sociedade globalizada impõe, e as atividades propostas devem ser tão variadas quanto as demandas, a ponto de não haver um método completamente autossuficiente, ou perfeito, como diz Furlanetto (2009).

Considerando as observações de Furlanetto (2009) e Sanches (2013) sobre o pós-método, a determinação de um método a ser seguido, seria, portanto, incompativel como uma prática pedagógica que busque conhecer o aluno para criar estratégias de aprendizagem, para no lugar disso, enquadrar todos no mesmo processo, sem considerar, além das múltiplas possibilidades de recursos e de abordagens, a diversidade de inteligências e de diferentes formas de aprender por parte dos alunos.

Para Bissaco (2015, p. 215), "o pós-método deve ser visto como uma alternativa para o método, pois toda pedagogia é local, ou seja, há que se observar o individuo local, os contextos institucionais, sociais e culturais. Existe nesses contextos uma particularidade única".

Em escolas de idiomas, ou até mesmo em escolas de ensino regulares particulares, a determinação de um método pode funcionar melhor, já que o aluno (ou os pais) poderiam buscar aquela escola, já por conta do método, isto é, sabendo que aquele estudante aprende melhor de determinada maneira, e que aquele método seria a opção mais adequada. 
O pensamento de Bissaco (2015) e também o de Kumaravadivelu (2001) podem ser usados para que se pense especialmente na escola pública brasileira, pois, diferentemente dos alunos de escolas particulares ou de escolas de idiomas, os alunos das escolas públicas dificilmente poderiam escolher a escola por conta do método de ensino de inglês, e nem poderiam trocar de escola caso não se adaptassem ao método da escola. Por isso, mais do que qualquer outra instituição de ensino, as escolas públicas precisam ter um olhar especial para os seus estudantes. Isto é, um olhar que busque perceber como eles aprendem, por quais temas se interessam, o que é importante na vida deles e como cada conhecimento pode ser agregador no contexto em que se inserem.

Dito isso, é importante destacar que a BNCC, como pode ser visto em Brasil (2017), não cita a tradução em nenhum lugar do seu texto, o que pode ser visto como uma lacuna deixada pelo documento, já que a tradução não pode ser descartada, mas discutida e se preciso revista e ressignificada. Há outro texto, que acompanha o da BNCC, mas que está destacado como não fazendo parte dela, e sim como material suplementar para o redator do currículo, o qual sim cita a tradução.

Para compreender essa menção, é necessário explicar a estrutura da Base: para cada ano, o componente "língua inglesa" é divido em cinco eixos: oralidade, leitura, escrita, conhecimentos linguísticos e dimensão intercultural. Cada um desses eixos se divide em unidades temáticas, que se subdividem em objetos de conhecimento, os quais se ramificam em habilidades. Além disso há, como dito, à parte da BNCC, comentários e possibilidades para o currículo (Brasil, 2017).

Especificamente, no $7^{\circ}$ ano, o eixo dimensão intercultural, unidade temática comunicação intercultural e objeto de conhecimento variação linguística, Brasil (2017, p. 251), estabelece como habilidade "reconhecer a variação linguística como manifestação de formas de pensar e expressar o mundo". Como comentário para essa habilidade (Brasil, 2017, n.p.) encontra-se o seguinte: "Essa habilidade é importante para apoiar o estudante no desenvolvimento da compreensão leitora e escritora, bem como no uso consciente e crítico, de ferramentas de tradução online".

A frase supracitada não está paginada, pois esses comentários e possibilidades para o currículo apenas foram encontrados em uma versão on line da Base disponivel como planilha de Excel. Além da ausência da tradução na Base, é interessante perceber como essa pequena citação como comentário, de segunda importância, aponta para o uso crítico de ferramentas de tradução on-line. Isto é, de alguma forma, muito discreta, se assume a tradução como uma possibilidade de recurso, não uma tradução nos moldes das que eram feitas em séculos passados, mas que acompanhe as problemáticas atuais e, portanto, significativa e interessante para os alunos.

Deste modo, a Base Nacional Comum Curricular (BNCC), no que tange ao ensinoaprendizagem de inglês, pode ser vista como um documento pós-método, na medida em que propõe o desenvolvimento de diversas habilidades, divididas e subdivididas em vários eixos e unidades temáticas, que tramam uma complexidade que muito dificilmente seria atendida com um único método.

A ideia de pós-método por si só, já vai na contramão de se utilizar o método da tradução (ou qualquer outro), já que o pós-método é justamente a oposição e a superação do método por uma prática mais crítica e atenta, no entanto, mesmo que se adote um método, o da tradução não é o mais adequado, na medida em que não é compativel com as demandas da contemporaneidade, já que atualmente, diferentemente do contexto do surgimento do método da tradução, como explicado anteriormente, com base em Gomes (2012), há uma variedade de textos e possibilidades de comunicação, que fazem parte da vida de muitos estudantes e devem fazer parte, também, da aprendizagem, e não podem ser abarcados pela tradução.

Em que pese esta incompatibilidade, a tradução como recurso pode ser utilizada de maneiras modernas e atrativas e contribuir para o desenvolvimento de habilidades linguísticas pelos estudantes. Consequentemente, também deve se desenvolver um senso crítico para com os textos, isto é, habilidades que expandam a ideia 
de compreensão, codificação e decodificação, para que o estudante possa fazer uso de uma comunicação que leve em conta seus aspectos sociais, locais ou globais, isto é, compreenda os contextos para se colocar como agente ativo em suas necessidades e possibilidades comunicativas e, portanto, sociais.

Deve-se destacar, conforme Souza (2007), que os recursos utilizados em aula devem propiciar ao aluno ir além, pesquisar, buscar novos conhecimentos e adquirir a cultura investigativa que o preparará para ser sujeito ativo na sociedade.

Acerca dessa função social da educação e do ensino-aprendizagem de inglês, Campos-Gonella (2007) corrobora ao afirmar que o professor de lingua inglesa deve considerar utilizar diversos recursos para o desenvolvimento de um conteúdo, empregar recursos autênticos, buscar uma aproximação cultural e a contextualização da língua, além de pensar no nivel dos alunos, assim como nas expectativas e interesses deles.

Uma ferramenta comumente usada para a tradução na internet é o Google Tradutor (https://translate.google.com.br/?hl=pt-BR), que mesmo sendo simples e de uso comum, pode ser utilizada como instrumento para o desenvolvimento da tradução consciente e critica que se busca nos alunos.

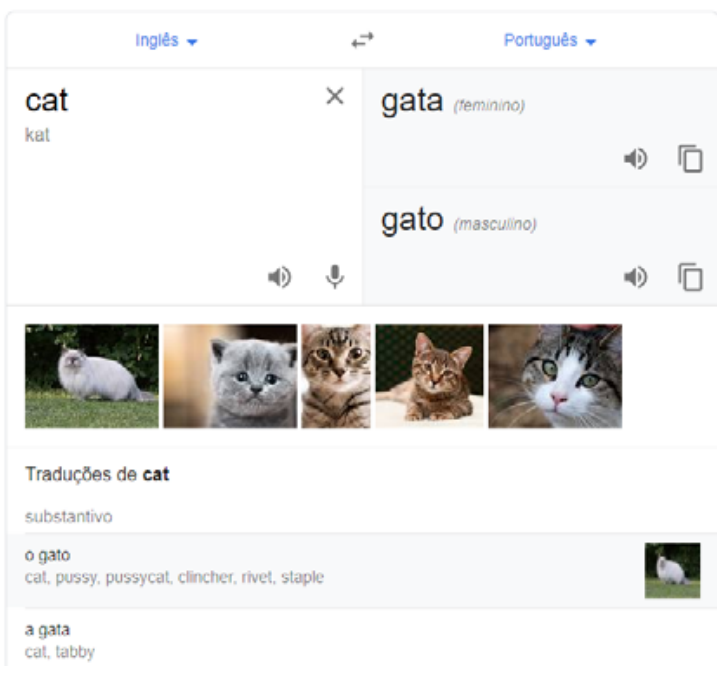

Figura 1 - Google Tradutor.

Fonte: Captura de imagem realizada pelo autor.

Como pode ser visto Figura 1, foi digitado no
Google Tradutorem inglês a palavra cat. Imaginandose um aluno traduzindo, ele se depararia com a questão de gênero que permeia as línguas, perceberia as imagens, que podem ajudar na fixação da palavra, poderia ouvir a pronúncia e até falar usando o microfone, além de verificar sinônimos, ea classificação gramatical da palavra, ou seja, há várias maneiras de explorar essa ferramenta e diversas questões a serem trabalhadas para que os alunos possam utilizá-la da maneira mais rica possivel.

Alguns sites e aplicativos usam a tradução em forma de game. Um exemplo é o Duolingo (https:// wwww.duolingo.com), que pode ser visto na Figura 2.

\section{Qual destas imagens é "manteiga"?}

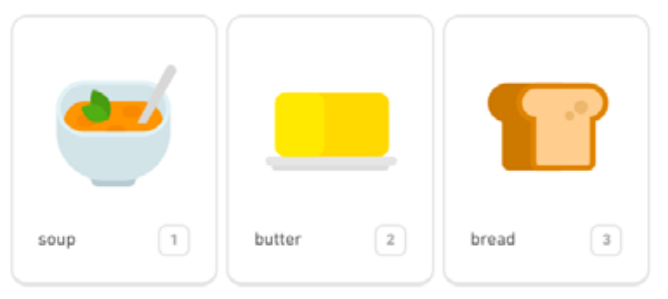

Figura 2 - Duolingo: tradução e associação. Fonte: Captura de imagem realizada pelo autor no site Duolingo.

No Duolingo, o usuário pode adicionar amigos e estabelecer metas. $\mathrm{O}$ formato de jogo tende a atrair 0 interesse dos alunos, e as atividades de tradução, envolvem as quatro habilidades listening, reading, speaking e writing - associando a imagens e com a possibilidade, por exemplo, de que professor e os alunos de uma mesma turma interajam, na funcionalidade Duolingo for Schools.

\section{Escreva em inglês:}

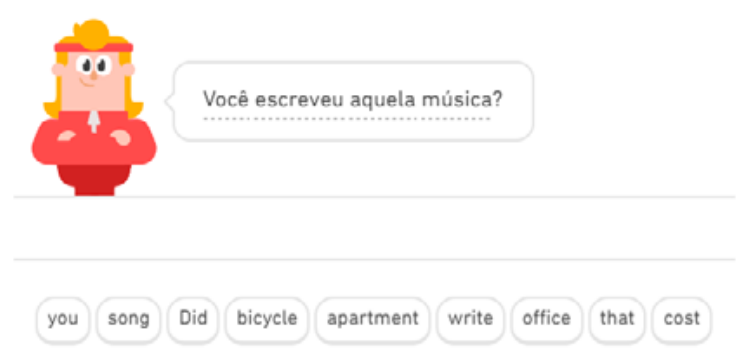

Figura 3 - Duolingo: tradução com banco de palavras. Fonte: Captura de imagem realizada pelo autor no site Duolingo. 
No Duolingo, os conteúdos estão divididos por unidades, o que facilita o uso em aula. Como pode ser visto na Figura 3, algumas atividades podem ser "puramente" de tradução, enquanto outras, como na Figura 2, mesclam tradução e associação de imagens, bem como compreensão e produção de textos orais etc.

Esses dois exemplos são jeitos de se usar a tradução como um recurso aliado ao processo de ensino-aprendizagem de inglês do século XXI, acompanhando as necessidades do aluno atual, sem extrapolar os limites de recurso e se tornar um método fechado, mas sim um recurso ressignificado, e por consequência, livre das mistificações e simplificações que herdara das práticas e contextos históricos anteriormente explicados.

A internet e as novas tecnologias possibilitam o uso de diversos recursos, e o professor tem o importante papel de considerar os conhecimentos prévios dos alunos, suas realidades, necessidades, para que a aprendizagem se dê de maneira contextualizada, significativa e atrativa.

\section{Considerações finais}

O objetivo dessa pesquisa foi entender o lugar da tradução no processo de ensino-aprendizagem de lingua inglesa do século XXI. Para isso, buscouse discutir a determinação de um método para as aulas de inglês, refletir acerca da tradução como método de ensino-aprendizagem de inglês, analisar a tradução como recurso didático das aulas de inglês.

Considerando a diversidade de contextos, alunos e, consequentemente, de inteligências, isto é, aptidões, interesses e formas de aprender, pode-se perceber que a definição de um método, sobretudo em escolas públicas de ensino regular, pode ser um limitador que acaba excluindo possibilidades mais adequadas do processo de ensino-aprendizagem de língua inglesa. Além disso, a tradução como método, foi pensada para um contexto diferente do atual, não dando mais conta das demandas contemporâneas.

O fato de o método da tradução ser usado por muito tempo, e até os dias atuais, de forma anacrônica, no bojo de um processo de perpetuação de velhas práticas que assombra a educação brasileira, acabou deixando-o com marcas que precisam ser analisadas com cuidado. No entanto, a tradução pode ser usada como um recurso capaz de proporcionar o desenvolvimento de habilidades linguísticas e seus usos práticos, sociais e contextualizados e percepções acerca, tanto da lingua materna, quanto da segunda lingua.

A própria BNCC não dá nenhum enfoque à tradução e, com a diversidade de habilidades que estabelece, acaba reforçando a falência do uso de um método para o ensino de inglês. Portanto, o lugar da tradução no processo de ensinoaprendizagem de inglês do século, certamente não é o de método, nem de protagonista, papel que ela pode ter representado bem no passado.

Porém, o reconhecimento dos fatores históricos e das novas possibilidades que as tecnologias propiciam, são fatores que o professor de inglês deve levar em conta ao olhar para a tradução e ao escolher os recursos que usará para suas aulas. Junto a isso, é importante se ter em vista as particularidades e as necessidades de seus alunos, para então conseguir utilizar a tradução, naquele que deve ser seu lugar neste processo: 0 de um recurso didático ao qual novos significados podem ser atribuídos, para que seja condizente com a realidade em que os alunos vivem, e adequadamente pertencente à complexidade que, ao processo de ensino-aprendizagem de inglês, essa realidade impõe.

\section{Referências}

Benjamin, W. (2018). Linguagem, tradução, literatura (filosofia, teoria e critica). (1. ed., Tradução de João Barrento). Autêntica Editora.

Bergmann, J. C. F., \& Lisboa, M. F. A. (2013). Teoria e Prática da Tradução. Editora InterSaberes.

Bissaco, C. M. (2015). Pós-método: o importante papel da reflexão do professor nas escolhas em sala de aula. Travessias, 23, 210-223. http://e-revista.unioeste.br/ index.php/travessias/article/download/11792/8779

Brasil. (2017) Base Nacional Comum Curricular. Ministério da Educação e Cultura (MEC). http://portal.mec. gov.br/index.php?option=com_docman\&view=download\&alias=79601-anexo-texto-bncc-reexportado-pdf-2\&category_slug=dezembro-2017-pdf\&ltemid=30192 
Campos-Gonella, C. O. (2007). A influência do material didático na motivação de aprendizes da língua inglesa em contexto de ensino público. São Carlos: [Dissertação de Mestrado, Universidade Federal de São Carlos]. http://www.leffa.pro.br/tela4/Textos/Textos/diserta_online/Cristiane_Campos_Gonella.pdf

Corrêa, T. H. (2017). "To be or not to be"? Uma análise da prática da oralidade nas aulas de língua inglesa das escolas públicas do estado de Minas Gerais: realidade ou utopia? PERcursos linguísticos, 7(14), 295-313. http:// periodicos.ufes.br/percursos/article/view/15625

Furlanetto, P. F. (2019). O professor global e o ensino da Lingua Inglesa: uma visão a partir do pós-método. InterSaberes.

Gomes, M. L. de C. (2012). Prefácio. In Lapkoski, G. A. de O. Do texto ao sentido: teoria e prática de leitura em lingua inglesa (pp. 7-8). InterSaberes.

Knechtel, M. do R. (2014). Metodologia da pesquisa em educação: uma abordagem teórico-prática dialogada. InterSaberes.

Lakatos, E. M., \& Marconi, M. A. (2017). Metodologia do trabalho científico: projetos de pesquisa/ pesquisa bibliográfica, teses de doutorado, dissertações de mestrado, trabalhos de conclusão de curso. Atlas.

Leffa, V. (2012). Ensino de línguas: passado, presente e futuro. Belo Horizonte: Revista de Estudos da Linguagem, 20(2), 389-411. http://periodicos.letras.ufmg.br/index. $\mathrm{php} / \mathrm{relin} /$ article/view/2755/2710

Lucindo, E. S. (2006). Tradução e ensino de linguas estrangeiras. Scientia Traductionis, 3, 1-11. https:// periodicos.ufsc.br/index.php/scientia/article/ view/12933/12064.

Marques, F. S. (2012). Ensinar e aprender inglês: o processo comunicativo em sala de aula. InterSaberes.

Pertel, T. (2009). Tradução e ensino aprendizagem de lingua inglesa: leitura e análise contrastiva como exercícios de construção de significados. Revista (Com) Textos linguisticos, n. especial, 135-144. https://periodicos.ufes.br/contextoslinguisticos/article/view/5269

Kumaravadivelu, B. (2001). Toward a Postmethod Pedagogy. TESOL Quarterly, 35(4), 537-560. http://Ww/w. bkumaravadivelu.com/articles\%20in\%20pdfs/2001\%20 Kumaravadivelu\%20Postmethod\%20Pedagogy.pdf

Roca, P (2009). Relações de simulação e relações de autenticidade no ensino de linguas vivas. In Pereira, R. C. M., \& Roca, P. Linguistica aplicada: um caminho com diferentes acessos (pp. 143-171). Editora Contexto.

Sanches, M. de F. G. (2011). As estratégias utilizadas no ensino de língua inglesa no pós método para nativos e imigrantes digitais. Augusto Guzzo Revista Acadêmica, 11, 50-59. http://fics.edu.br/index.php/augusto_guzzo/ article/view/151/210
Souza, S. E. de. (2007). O uso de recursos didáticos no ensino escolar. I Encontro de Pesquisa em Educação, IV Jornada de Prática de Ensino, XIII Semana de Pedagogia da UEM: "Infância e Práticas Educativas", Maringá, PR, Brasil. http://www.dma.ufv.br/downloads/MAT\%20 103/2015-II/slides/Rec\%20Didaticos\%20-\%20MAT\%20 103\%20-\%202015-II.pdf

Tecchio, I. \& Bittencourt, M. (2011). A Tradução no Ensino-Aprendizagem de Linguas Estrangeiras. Revista Magistro, 2(1). http://publicacoes.unigranrio.edu.br/ index.php/magistro/article/viewFile/1471/765

TERRA, M. R. (2010). Tradução \& aprendizado de lingua estrangeira: o ponto de vista do aluno. Trabalhos em Linguistica Aplicada, 49(1), 69-85. https://doi.org/10.1590/ S0103-18132010000100006

Uphoff, D. (2008). A história dos Métodos de Ensino de Inglês no Brasil. In Bologninl, C. Z. A lingua inglesa na escola. Discurso e ensino (pp. 9-15). Mercado de Letras. https://edisciplinas.usp.br/pluginfile.php/4490214/ mod_resource/content/5/Uphoff\%202008.pdf

\section{Lucas Alves Selhorst}

Licenciado em Letras - Inglês pelo Centro Universitário Leonardo da Vinci (UNIASSELVI), em Tubarão, SC, Brasil: mestrando em Ciências da Linguagem na Universidade do Sul de Santa Catarina (UNISUL), em Palhoça, SC, Brasil; bolsista Capes/Prosuc; professor de Inglês na rede municipal de Imarui, em Imarui, SC, Brasil.

\section{Endereço para correspondência}

Lucas Alves Selhorst

Escola de Ensino Fundamental Municipal Professora Larice Cavalcanti Caldas

Estrada geral, sem número

Aratingaúba, 88770-000

Imarui, SC, Brasil

Os textos deste artigo foram revisados pela Poá Comunicação e submetidos para validação do autor antes da publicação. 